\title{
Expression of genes encoding mitochondrial proteins can distinguish nonalcoholic steatosis from steatohepatitis
}

\author{
Piotr Bragoszewski ${ }^{1}$, Andrzej Habior ${ }^{1}$, Bozena Walewska-Zielecka ${ }^{2}$ and \\ Jerzy Ostrowski ${ }^{1 \bowtie}$ \\ ${ }^{1}$ Department of Gastroenterology and Hepatology, Medical Center for Postgraduate Education and Maria Sklo- \\ dowska-Curie Memorial Cancer Center and Institute of Oncology, Warszawa, Poland; ${ }^{2}$ Department of Immun- \\ opathology, National Institute of Health, Warszawa, Poland
}

Received: 01 February, 2007; revised: 10 April, 2007; accepted: 23 April, 2007

available on-line: 15 May, 2007

\begin{abstract}
In patients without substantial alcohol use, triglyceride accumulation in the liver can lead to nonalcoholic fatty liver disease (NAFLD) that may progress to nonalcoholic steatohepatitis (NASH). The differential diagnosis between NAFLD and NASH can be accomplished only by morphological examination. Although the relationship between mitochondrial dysfunction and the progression of liver pathologic changes has been described, the exact mechanisms initiating primary liver steatosis and its progression to NASH are unknown. We selected 16 genes encoding mitochondrial proteins which expression was compared by quantitative RT-PCR in liver tissue samples taken from patients with NAFLD and NASH. We found that 6 of the 16 examined genes were differentially expressed in NAFLD versus NASH patients. The expression of hepatic HK1, UCP2, $M E 2$, and ME3 appeared to be higher in NASH than in NAFLD patients, whereas HMGCS2 and hnRNPK expression was lower in NASH patients. Although the severity of liver morphological injury in the spectrum of NAFLD-NASH may be defined at the molecular level, expression of these selected 6 genes cannot be used as a molecular marker aiding histological examination. Moreover, it is still unclear whether these differences in hepatic gene expression profiles truly reflect the progression of morphological abnormalities or rather indicate various metabolic and hormonal states in patients with different degrees of fatty liver disease.
\end{abstract}

Keywords: NAFLD, NASH, gene expression, mitochondria

\section{INTRODUCTION}

More than $75 \%$ of obese adults and $50 \%$ of obese children can be affected by triglyceride accumulation in the liver that leads to hepatic steatosis, termed nonalcoholic fatty liver disease (NAFLD). NAFLD may progress to nonalcoholic steatohepatitis (NASH) when hepatocyte lipid accumulation is associated with tissue infiltration by inflammatory cells, fibrosis, and other pathologic abnormalities. Both NAFLD and NASH are essentially asymptomatic conditions. Although they are accompanied by elevated serum aminotransferase activities, the degree of abnormality in liver function tests does not correlate with liver histology. Thus, the progres- sion from NAFLD to NASH can be recognized only by morphological examination (Harrison et al., 2003; Neuschwander-Tetri \& Caldwell, 2003; Adams et al., 2005; Pessayre \& Fromenty, 2005; Angulo, 2006; Bogdanova et al., 2006; Ekstedt et al., 2006).

As with many other complex disorders, NAFLD is likely an acquired response to dietetic and environmental factors modified by genetic predisposition. Although liver steatosis is associated with hyperlipidemia and insulin resistance (Bogdanova et al., 2006; Ekstedt et al., 2006), the mechanisms leading to NAFLD are not yet fully understood. It is hypothesized that hepatic lipid accumulation resulting from insulin resistance in adipocytes and muscles leads to increased mitochondrial fatty acid oxida-

Corresponding author: J. Ostrowski, Department of Gastroenterology and Hepatology, Cancer Center, Roentgena 5, 02781 Warszawa, Poland; phone: (48 22) 546 2575; fax: (48 22) 644 0209; e-mail: jostrow@warman.com.pl Abbreviations: NAFLD, nonalcoholic fatty liver disease; NASH, nonalcoholic steatohepatitis; ROS, reactive oxygen species; RT-PCR, reverse transcription-polymerase chain reaction. 
tion and the production of reactive oxygen species (ROS). These mitochondrial abnormalities may promote hepatic oxidative stress, causing functional and morphological hepatic changes. Further impairment of mitochondrial function may play a key role in the progression from NAFLD to NASH (Caldwell et al., 1999; Perez-Carreras et al., 2003; Sreekumar et al., 2003; Browning \& Horton, 2004; Pessayre et al., 2004; Pessayre \& Fromenty, 2005; Begriche et al., 2006).

Cell- and developmental-stage-specific, metabolism-related changes in gene expression determine the diversity in structure, metabolism and adaptive processes of the organism. Although a disease phenotype is the result of molecular changes that arise from aberrations in the cells' adaptive capabilities due to changes in genetic information (mutations and/or epigenetic changes) and environmental factors, molecular mechanisms underlying most disorders remain largely unknown. Therefore, modern medicine employs mostly anatomical, microscopic and metabolic levels of phenotype imaging. Introduction of molecular diagnostics into clinical practice would improve our understanding of disease development but the molecular classification of disease would be only warranted when it would lead to the practical optimization of prevention, detection and/or treatment of a disorder.

To reach a better understanding of the relationship between mitochondrial dysfunction and the progression of liver pathologic changes, it is essential to determine if the severity of liver morphological injury can also be defined at the molecular level. This study compared the expression of selected genes encoding mitochondrial proteins in liver tissue samples from patients with NAFLD or NASH. Although the severity of liver injury in the spectrum of NAFLD-NASH may be defined at the molecular level, estimation of gene expression cannot support histological diagnosis in individual patients.

\section{MATERIALS AND METHODS}

Patients. Thirty-one untreated, overweight or obese patients (27 males and 4 females) aged 26-63 years were included in the study. They were evaluated at the Department of Gastroenterology and Hepatology for long-term liver dysfunction expressed by elevated liver function tests and changes in liver ultrasounds suggesting fat accumulation. All patients were HBV- and HCV-negative. Patients with known causes of liver steatosis such as excessive $(>20 \mathrm{~g} / \mathrm{d})$ alcohol abuse, the use of certain medications, metabolic disorders, and autoimmune liver disorders were excluded. Informed consent was obtained from each patient included in the study, and the study protocol was approved by the Bioethical
Committee of the Medical Center for Postgraduate Education.

Liver biopsies. The diagnosis of liver steatosis was confirmed by percutaneous liver biopsy performed in all subjects with a 1.6-mm Menghinitype biopsy needle. Liver samples were routinely processed, sectioned, and stained with hematoxilineosin and Manson's trichrome. All biopsies were studied by the same liver pathologist (B.W.-Z.). Each liver biopsy was assigned to one of two diagnostic categories: NAFLD or NASH. Histological features including steatosis, portal and lobular inflammation, fibrosis, and hepatocyte ballooning were assessed and scored according to Brunt for histological diagnosis of NASH (Brunt et al., 1999). NAFLD was defined when the biopsy showed steatosis alone or steatosis with nonspecific inflammation. Two-thirds of each biopsy section was used for histopathological examination, and the remaining tissue was used for the gene expression study.

RT-real-time PCR analysis. Specific RNA concentrations were determined by reverse transcriptione (RT)-real-time PCR. After disintegration of frozen tissue in liquid nitrogen with a teflon pestle, total RNA was isolated from hepatic biopsies using the RNeasy Kit and QIAshredder columns (Qiagen $\mathrm{GmbH}$, Hilden, Germany). Reverse transcription was performed with the SuperScript II Reverse Transcriptase (Invitrogen Co., Carlsbad, CA, USA) reagent set according to the manufacturer's instructions. Quantitative evaluation of mRNA was performed on an ABI Prism 7000 Sequence Detection System using SYBR Green PCR Master Mix reagent (Applied Biosystems, Foster City, CA, USA) in a $25-\mu 1$ reaction mixture containing $12.5 \mu \mathrm{l} 2 \times$ SYBR Green PCR Master Mix, $5 \mu \mathrm{l}$ cDNA, and $50 \mathrm{nM}$ primers. Oligonucleotide primers for the analyzed gene transcripts were designed using Primer Express Software (Applied Biosystems) and are listed in Table 1. For each run, standard curves were generated for a primer set by serial dilution of pooled cDNA to counterbalance variations in PCR reaction efficiency. Melting curves were generated after each reaction to verify melting temperatures of the amplicon. The purity of the RTPCR product was additionally verified by agarose gel electrophoresis.

To normalize nonspecific variations in realtime PCR, the normalization factor was calculated as the geometric mean of RNA concentrations of 3 control genes, glyceraldehyde-3-phosphate dehydrogenase $(G A P D H)$, ubiquitin $C(U B C)$ and succinate dehydrogenase complex, subunit A (SDHA) (Vandesompele et al., 2002). They were selected from sets of control genes described as the most stably expressed in liver and other tissues (Vandesompele et al., 2002; Kim \& Kim, 2003). 
Table 1. Oligonucleotide sequences of primer pairs used in real-time tients fulfilled the criteria for NASH. As RT-PCR reactions

\begin{tabular}{|c|c|c|}
\hline \multirow{2}{*}{$\begin{array}{l}\text { Gene } \\
A L D H 4\end{array}$} & \multicolumn{2}{|r|}{ Primer sequence } \\
\hline & Forward: & 5'-GAATCCTCCTCTGCCTGGGA \\
\hline & Reverse: & $5^{\prime}$-TCTGTGGGAGGAATCGTGGT \\
\hline \multirow{2}{*}{ BNIP3 } & Forward: & $5^{\prime}-$ АССТСCACCAGCACСТTTTG \\
\hline & Reverse: & $5^{\prime}-\mathrm{GCCACCCCAGGATCTAACAG}$ \\
\hline \multirow[t]{2}{*}{ GAPDH } & Forward: & $5^{\prime}$-GAAGGTGAAGGTCGGAGTC \\
\hline & Reverse: & $5^{\prime}$-GAAGATGGTGATGGGATTTC \\
\hline \multirow[t]{2}{*}{ HK1 } & Forward: & $5^{\prime}$-TTGGGAGAGCTGGTTCGACT \\
\hline & Reverse: & $5^{\prime}$-TTAAACTTCCCTCGGGTGAGC \\
\hline \multirow[t]{2}{*}{ HMGCS2 } & Forward: & 5'-GCTACGGTGGTACTGCCTCC \\
\hline & Reverse: & $5^{\prime}-$ GACGGCAATGTCTCCACAGA \\
\hline \multirow[t]{2}{*}{ ME2 } & Forward: & $5^{\prime}-\mathrm{CGCCGGGTGTACCACCT}$ \\
\hline & Reverse: & $5^{\prime}-$ GTCGACATGCCAAAGTACAAGTG \\
\hline \multirow[t]{2}{*}{ ME3 } & Forward: & $5^{\prime}-\mathrm{TGAAGAAGCGCGGATACGA}$ \\
\hline & Reverse: & $5^{\prime}$-GATTAGGCCGTGGATTCCAAG \\
\hline \multirow[t]{2}{*}{ MT-АTP 6} & Forward: & $5^{\prime}-\mathrm{TAGCCATACACAACACTAAAGGACGA}$ \\
\hline & Reverse: & 5'-GGGCATTTTTAATCTTAGAGCGAAA \\
\hline \multirow[t]{2}{*}{ MT-CO1 } & Forward: & $5^{\prime}$-GACGTAGACACACGAGCATATTTCA \\
\hline & Reverse: & $5^{\prime}$-AGGACATAGTGGAAGTGAGCTACAAC \\
\hline \multirow[t]{2}{*}{$M T-C Y B$} & Forward: & $5^{\prime}$-ATCACTCGAGACGTAAATTATGGCT \\
\hline & Reverse: & $5^{\prime}$-TGAACTAGGTCTGTCCCAATGTATG \\
\hline \multirow[t]{2}{*}{ MT-ND1 } & Forward: & $5^{\prime}$-CCACCTCTAGCCTAGCCGTTTA \\
\hline & Reverse: & $5^{\prime}$-GGGTCATGATGGCAGGAGTAAT \\
\hline \multirow[t]{2}{*}{$M T-N D 6$} & Forward: & $5^{\prime}$-CAAACAATGTTCAACCAGTAACCACTAC \\
\hline & Reverse: & $5^{\prime}$-ATATACTACAGCGATGGCTATTGAGGA \\
\hline \multirow[t]{2}{*}{ MT-RNR1 } & Forward: & $5^{\prime}$-TAGAGGAGCCTGTTCTGTAATCGAT \\
\hline & Reverse: & $5^{\prime}$-CGACCCTTAAGTTTCATAAGGGCTA \\
\hline \multirow[t]{2}{*}{ NNT } & Forward: & 5'-GCTGACATGCCCGTCGTTA \\
\hline & Reverse: & $5^{\prime}-$ CCCACGATGGTCAGCAGATT \\
\hline \multirow[t]{2}{*}{$h n R N P K$} & Forward: & $5^{\prime}-\mathrm{CAACCAGCCAGCTCCCACTCG}$ \\
\hline & Reverse: & 5'-GTCCTCGGCGGTCATCAAACATC \\
\hline \multirow[t]{2}{*}{$S D H A$} & Forward: & $5^{\prime}$-GCGAAAGGTTTATGGAGCGAT \\
\hline & Reverse: & 5'-GCCTCTTCCTTCTCGGATCTC \\
\hline \multirow[t]{2}{*}{ SUPV3L1 } & Forward: & $5^{\prime}$-GTTGAATTTGGAGGGCTTTCC \\
\hline & Reverse: & $5^{\prime}$-GCTGGGTGGCTCAGTAGCTT \\
\hline \multirow[t]{2}{*}{$U B C$} & Forward: & 5'-ATTTGGGTCGCGGTTCTTG \\
\hline & Reverse: & $5^{\prime}$-TGCCTTGACATTCTCGATGGT \\
\hline \multirow[t]{2}{*}{ UCP2 } & Forward: & $5^{\prime}$-ACGGGACACCTTTAGAGAAGCTT \\
\hline & Reverse: & 5'-ACTTTCTCCTTGGATCTGTAACCG \\
\hline
\end{tabular}

Statistical analysis. All data were summarized using standard methods: mean and S.D. for continuous variables, and median and range for non-normally distributed data. The results were analyzed with the Student's t-test and Mann-Whitney $U$ test, respectively. The non-parametric Spearman's correlation coefficient was used to assess significant correlations among variables. $P$ values of less then 0.05 were considered significant. Calculations were done using Stata v. 6.0 (Stata Corporation 1999, College Station, TX, USA).

\section{RESULTS}

Sixteen of the 31 patients had pathological diagnosis of NAFLD, and the remaining 15 pa- shown in Table 2, there were no differences in anthropometric or biochemical tests between NAFLD and NASH patients.

To investigate whether expression of mitochondrial-related genes can differentiate NAFLD and NASH groups, total hepatic RNA was isolated, and 16 transcripts were quantified using real-time RT-PCR. Of these, 6 were mitochondrial-encoded RNAs, and 10 were nuclear-encoded RNAs. The mitochondrial genes (MT-ATP6, MT-CO1, MT-CYB, MT-ND1 and MT-ND6) encode polypeptides and ribosomal $12 S$ RNA (MT-RNR1). Nuclear genes were as follows: HMGCS2 which encodes mitochondrial 3-hydroxy-3-methylglutaryl-coenzyme A synthase 2 converting hepatic acetyl-CoA to ketone bodies; $A L D H 4 A 1$ which encodes aldehyde dehydrogenase 4 family, member A1, the protein which catalyzes the second step of the proline degradation pathway; BNIP3 which encodes BCL2/adenovirus E1B $19 \mathrm{kDa}$ interacting protein 3 responsible for the protection from virally-induced cell death; HK1 which encodes hexokinase localized to the outer membrane of mitochondria and committing glucose to the glycolytic pathway by glucose phosphorylation; ME2 and ME3 which encode mitochondrial isoforms of malic enzyme; NNT which encodes nicotinamide nucleotide transhydrogenase, part of the energy-transfer system of the respiratory chain; SUPV3L1 which encodes an NTP-dependent RNA/DNA helicase; UCP2 which encodes a member of a family of the inner mitochondrial membrane carriers; $h n R N P K$ which encodes heterogeneous nuclear ribonucleoprotein $\mathrm{K}$ protein acting in several sub-cellular compartments, including mitochondria and integrating cellular signaling cascades with nucleic acid-directed processes (http:// www.ncbi.nlm.nih.gov/entrez/query.fcgi?db=gene).

The levels of 12 transcripts, including all transcripts encoded by the mitochondrial genome, were similar in the liver tissues affected by NAFLD and NASH. However, six genes encoded by the nuclear genome were differentially expressed between NAFLD and NASH patients. HMGCS2 and hnRNPK showed lower expression in liver tissue samples obtained from NASH patients compared to NAFLD patients, whereas $H K 1, U C P 2, M E 2$, and ME3 had 
Table 2. Anthropometric and biochemical characteristics of the studied patients divided according to histological findings

\begin{tabular}{lccc}
\hline & $\begin{array}{c}\text { NAFLD } \\
(\mathrm{n}=16)\end{array}$ & $\begin{array}{c}\text { NASH } \\
(\mathrm{n}=15)\end{array}$ & $P$ \\
\hline Age (years)* & $38(10)$ & $42(11)$ & $13 / 2$ \\
Male/Female & $14 / 2$ & $28.8(2.8)$ & 0.33 \\
BMI $\left(\mathrm{kg} / \mathrm{m}^{2}\right)^{*}$ & $29.0(6.1)$ & $0.94(0.05)$ & 0.92 \\
WHR $^{*}$ & $0.90(0.07)$ & $30.6(6.5)$ & 0.19 \\
BIA $(\%)^{*}$ & $26.4(9.7)$ & $5.0(0.6)$ & 0.26 \\
Fasting serum glucose $(\mathrm{mmol} / \mathrm{L})^{*}$ & $4.8(0.7)$ & $12.7(3.4-266.2)$ & 0.52 \\
Fasting serum insulin $(\mu \mathrm{IU} / \mathrm{mL}) \#$ & $10.1(4.4-16.8)$ & $3.1(0.6-76.3)$ & 0.34 \\
HOMA\# & $2.2(0.8-4.4)$ & $128(60-312)$ & 0.31 \\
ALT $(\mathrm{IU} / \mathrm{L}) \#$ & $93.5(32-205)$ & $66(22-184)$ & 0.47 \\
AST (IU/L)\# & $42(16-182)$ & $207(153-367)$ & 0.09 \\
Serum cholesterol $(\mathrm{mg} / \mathrm{dL}) \#$ & $215(135-290)$ & $162(38.0)$ & 0.67 \\
Serum trigliceride $(\mathrm{mg} / \mathrm{dL})^{*}$ & $132(54.7)$ & 0.08 \\
\hline
\end{tabular}

*Values expressed as mean (S.D.) and compared with Student's $t$-test; \#values expressed as median (range) and compared with MannWhitney $U$ test.

Abbreviations: NAFLD, patients with simple steatosis or steatosis with nonspecific inflammation; NASH, patients with nonalcoholic steatohepatitis; BMI, body mass index; WHR, waist-to-hip ratio; BIA, bioelectrical impedance analysis of body fat; HOMA, homeostatic assessment index; ALT, alanine aminotransferase; AST, aspartate aminotransferase.

higher expression in NASH versus NAFLD patients (Fig. 1).

\section{DISCUSSION}

Mitochondria are most notably involved in ATP production but also contribute to thermogenesis, free radical production, calcium homeostasis, and apoptosis (Duchen, 2004). It was recently proposed that altered mitochondrial biogenesis leads to a decreased capacity for oxidative phosphorylation and may be involved in the pathogenesis of obesity, age-related resistance to insulin, and the development of type 2 diabetes mellitus (Kelley et al., 2002; Petersen et al., 2003, Stump et al., 2003). Mitochondrial dysfunction is also thought to be a key pathophysiological mechanism leading to fatty liver disease (Caldwell et al., 1999; Perez-Carreras et al., 2003; Sreekumar et al., 2003; Browning \& Horton, 2004; Pessayre et al., 2004; 2005; Begriche et al., 2006). However, the exact mechanisms initiating primary liver steatosis and its development to steatohepatitis are not well understood.

Mammalian mitochondrial DNA encodes seven subunits of NADH dehydrogenase, one subunit of cytochrome $c$ reductase, three subunits of cytochrome $c$ oxidase, two subunits of ATP synthase, and two ribosomal RNAs (Taanman, 1999). However, mitochondria contain about 1000 proteins, and the majority of them are encoded by nuclear DNA (Goffart \& Wiesner, 2003). These proteins are synthesized in the cytoplasm and are imported into the mitochondria. Some of them are localized exclusive- ly within the mitochondria, whereas others exhibit multi-compartment localization (Mootha et al., 2003).

In this study we compared the relative levels of RNAs encoding mitochondrial proteins to determine whether expression of mitochondrial-related genes can differentiate NAFLD from NASH. Because we were searching for unknown potential genetic markers, we selected 16 genes (6 genes encoded by the mitochondrial genome and 10 genes encoded by the nuclear genome) that represent different mitochondrial functions.

Although damage of mitochondrial DNA and direct inactivation of all respiratory enzyme complexes were found in liver tissue from patients with NASH compared to healthy liver (Perez-Carreras et al., 2003), our study showed that the levels of mitochondrial-encoded RNAs were similar in liver affected by NASH compared with NAFLD. However, of 10 genes encoded by the nuclear genome, 6 were differentially expressed between NAFLD and NASH patients (Fig. 1). HMGCS2 and $h n R N P K$ showed decreased expression in liver samples from NASH patients compared to NAFLD patients, whereas HK1, UCP2, ME2, and ME3 showed increased expression in NASH versus NAFLD.

HMGCS2 encodes the mitochondrial protein 3-hydroxy-3-methylglutaryl-CoA synthase 2, which is involved in the degradation of ketone bodies and the metabolism of lipids, valine, leucine, isoleucine, and acetyl-CoA. The expression level of HMGCS2 is determined by circulating hormone and fatty acid levels. HMGCS2 expression is induced by both starvation and a high-fat diet and is inhibited by insulin (Camarero et al., 2006). We found that the 

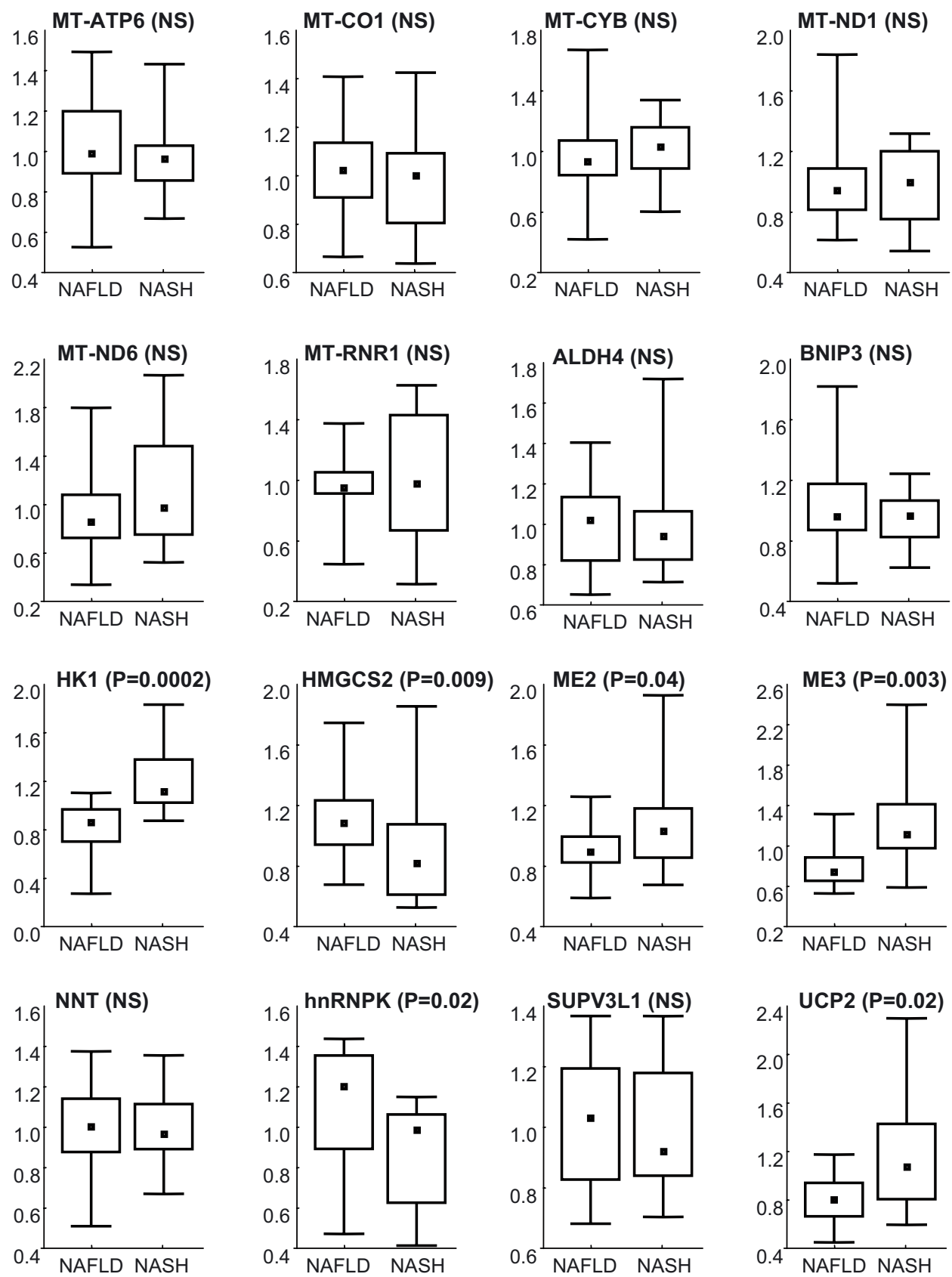

Figure 1. Relative mRNA expression of selected genes in liver specimens from patients with NALFD or NASH.

The quantitative RT-PCR analysis examined 16 selected transcripts. Total RNA was reverse-transcribed using SuperScript II reverse transcriptase (Invitrogen), and the real-time PCR used the double-stranded DNA-specific dye SYBR Green I. Statistical differences between mean values were assessed by the Mann-Whitney $U$ test. Data are presented in the boxplots, composed of medians of relative mRNA expression levels, their lower and upper quartiles (boxes), and minimum and maximum data values (whiskers). Medians were considered to be different if $P<0.05$. N.S., not significant.

expression of HMGCS2 was significantly lower in NASH patients than in NAFLD patients. Although there were no significant differences in serum insulin level between NAFLD and NASH patients, the relative level of HMGCS2 significantly correlated with the serum insulin level $(\mathrm{R}=-0.553 ; P=0.009)$. This observation raises a question about the significance of interaction between insulin and expression of HMGCS2 on the hepatic level.
By sensing and integrating signals from multiple kinase cascades to nucleic acid-dependent processes, heterogeneous nuclear ribonucleoprotein $\mathrm{K}$ (hnRNP-K) likely regulates multiple pathways of gene expression. Some of the hnRNP-K-regulated genes are involved in mitogenic responses and tumorigenesis (Ostrowski \& Bomsztyk, 2003; Bomsztyk et al., 2004; Carpenter et al., 2006). As shown recently, several proteins that are complexed with 
hnRNP-K localize to the mitochondria (Mikula et al., 2006). These include outer and inner membrane proteins, mitochondrial F1 complex protein, components of cytochrome $b-c 1$, and heat shock proteins. We also demonstrated that hnRNP-K interacts with many nuclear transcripts, including ucp 2 mRNA, preferentially through the $3^{\prime}$ untranslated regions, and with sense and antisense mitochondrial transcripts (Klimek-Tomczak et al., 2004). This highly specific, direct binding of transcripts to hnRNP-K is mediated by a consensus sequence composed of three Crich patches. hnRNP-K may be involved in cytoplasmic translation of mitochondrial proteins that can be exemplified by the insulin-induced translation of UCP2 protein (Ostrowski et al., 2004). Moreover, acting as a scaffolding protein, hnRNP-K can modulate functions of its molecular partners within mitochondria. We found that the expression of $h n R N P-K$ was significantly lower in NASH than in NAFLD.

Reactive oxygen species (ROS) are produced by all eukaryotic cells, predominantly during mitochondrial respiration (McLennan \& Degli Esposti, 2000). Mitochondrial hexokinases (HKs) catalyze the first step of glucose metabolism, coupling extramitochondrial glycolysis to intramitochondrial oxidative phosphorylation by selective utilization of intramitochondrial ATP (Meyer et al., 2006). HK activity prevents oxidative stress by reducing ROS generation (Perez-Carreras et al., 2003) and controls apoptosis in mammalian cells (Robey \& Hay, 2006). In our study, HK1 was found to be more highly expressed in liver samples from NASH patients than in samples from NAFLD patients.

The UCP2 protein belongs to a superfamily of inner mitochondrial membrane carriers that includes other uncoupling proteins (UCP1-5) as well as oxoglutarate and ADP/ATP transporters (Krauss et al., 2005). UCP2 gene knockout mice had higher levels of ROS, and in genetically obese mice increased hepatic expression of UCP2 was associated with a higher rate of proton leakage and reduced ATP stores within hepatic mitochondria (Argyropoulos \& Harper, 2002). The ob/ob UCP2PP-/-PP mice had higher levels of ATP and increased glucose-stimulated insulin secretion (Zhang et al., 2001). Although lack of UCP2 expression in the livers of ob/ob mice does not affect the severity of fatty liver changes (Baffy et al., 2002), the involvement of UCP2 in a host of metabolic processes including regulation of metabolic pathways, ROS production, and response to tissue injury is generally accepted (Saleh et al., 2002; Mattiasson et al., 2003; de Bilbao et al., 2004; Horimoto et al., 2004; Krauss \& Zhang, 2005). Thus, like HK1, UCP2 encodes a protein that contributes to the regulation of mitochondrial ROS production. The expression of UCP2 was higher in our patients with NASH than in patients with NAFLD.
Malic enzyme (ME) is considered a lipogenic enzyme whose activity correlates with the synthesis of fatty acids (Diez-Fernandez et al., 1996; Mounier \& Posner, 2006). In mammalian cells, one cytosolic (ME1) and two mitochondrial (ME2 and ME3) isoforms exist. MEs catalyze the oxidative decarboxylation of L-malate to pyruvate using $\mathrm{NAD}^{+}$or $\mathrm{NADP}^{+}$ as a cofactor. Mitochondrial MEs supply sufficient pyruvate for the Krebs cycle (Pongratz et al., 2007) and are involved in the maintenance of the cellular redox state (Sanz et al., 1997). Expression of ME is regulated in synergy by insulin and glucose (Dentin et al., 2005). Genes encoding ME2 and ME3 exhibited higher expression in NASH than in NAFLD.

NASH patients are unable to recover from a modest depletion in ATP (Fromenty et al., 2004). This reduction in ATP production can result from uncoupling of oxidative phosphorylation by superoxide-activated UCP2 to prevent excessive ROS production (Chan \& Kashemsant, 2006). In this light, the increased hepatic expression of UCP2 and HK1 in NASH patients compared with NAFLD patients might reflect a compromise in ATP synthesis that leads to decreased levels of mitochondrial ROS and increased oxidation of hepatic fatty acids (Fromenty et al., 2004; Begriche et al., 2006; Chan \& Kashemsant, 2006). Consequently, higher expression of ME2 and ME3 in NASH than in NAFLD might activate the Krebs cycle by pyruvate carboxylase flux to compensate for mitochondrial fuel production through other metabolically-derived messengers (Pongratz et al., 2007).

Nearly all diseases are genetically conditioned, and can be assigned to one of three classes: 1) chromosomal disorders, 2) single-gene disorders, and 3) multifactorial disorders. Multifactorial (complex) diseases are a result of many genetic determinants with low expression and environmental factors which contribute to the enhancement of the expression of genetic changes. This may mean that each individual, through changing defense and adaptive mechanisms, can react in a unique way to disease-inducing factors, particularly at the molecular level. However, the molecular mechanisms underlying most diseases remain largely unknown, and their elucidation requires the introduction of molecular diagnostics into clinical practice. Therefore, molecular methods may allow a more efficient health care system, both for the individual patient and the population as a whole (Ostrowski, 2006).

Although neither biochemical nor anthropometrical measurements can recognize the progression of liver pathology in nonalcoholic hepatic steatosis, we found that the severity of liver injury in the spectrum of NAFLD-NASH may be defined at the molecular level. Furthermore, the differentially expressed HK1, UCP2, ME2, and ME3 are in 
agreement with the hypothesis that mitochondrial ROS production is one of the cellular mechanisms involved in progression from NAFLD to NASH. On the other hand, the extent of variation in gene expression between individuals was quite high, making it impossible to discriminate effectively between these two groups of tissues. As such, none of the analyzed genes alone or in combination with others (not shown) has practical value as a molecular marker of the progression from NAFLD to NASH in terms of supporting the histological diagnosis.

Moreover, it is unclear whether the observed differences in hepatic gene expression reflect the progression of morphological abnormalities or whether they indicate various metabolic and hormonal states in patients with different degrees of fatty liver disease. Further studies should resolve the question of whether the described molecular changes reflect pathophysiological mechanisms involved in the generation of NASH or are just consequences of the progression from NAFLD to NASH.

\section{Acknowledgements}

This work was supported by CMKP grant (501-1-1-09-23/04) and grant from the Foundation Supporting Polish Gastroenterology. J.O.'s work was also supported by a SCHOLAR GRANT from the Foundation for Polish Science.

\section{REFERENCES}

Adams LA, Lymp JF, St Sauver J, Sanderson SO, Lindor KD, Feldstein A, Angulo P (2005) The natural history of nonalcoholic fatty liver disease: a population-based cohort study. Gastroenterology 129: 113-121.

Angulo P (2006) NAFLD, obesity, and bariatric surgery. Gastroenterology 130: 1848-1852.

Argyropoulos G, Harper ME (2002) Uncoupling proteins and thermoregulation. J Appl Physiol 92: 2187-2198.

Baffy G, Zhang CY, Glickman JN, Lowell BB (2002) Obesity-related fatty liver is unchanged in mice deficient for mitochondrial uncoupling protein 2. Hepatology 35: 753-761.

Begriche K, Igoudjil A, Pessayre D, Fromenty B (2006) Mitochondrial dysfunction in NASH: causes, consequences and possible means to prevent it. Mitochondrion 6: $1-28$.

Bogdanova K, Poczatkova H, Uherkova L, Riegrova D, Rypka M, Feher J, Marchesini G, Vesely J (2006) Nonalcoholic fatty liver disease (NAFLD) - A novel common aspect of the metabolic syndrome. Biomed Pap Med Fac Univ Palacky Olomouc Czech Repub 150: 101-104.

Bomsztyk K, Denisenko O, Ostrowski J (2004) hnRNP K: one protein multiple processes. Bioessays 26: 629-638.

Browning JD, Horton JD (2004) Molecular mediators of hepatic steatosis and liver injury. J Clin Invest 114: 147152.

Brunt EM, Janney CG, Di Bisceglie AM, NeuschwanderTetri BA, Bacon BR (1999) Nonalcoholic steatohepatitis: a proposal for grading and staging the histological lesions. Am J Gastroenterol 94: 2467-2474.

Caldwell SH, Swerdlow RH, Khan EM, Iezzoni JC, Hespenheide EE, Parks JK, Parker WD Jr (1999) Mitochondrial abnormalities in non-alcoholic steatohepatitis. J Hepatol 31: $430-434$.

Camarero N, Mascaro C, Mayordomo C, Vilardell F, Haro D, Marrero PF (2006) Ketogenic HMGCS2 Is a c-Myc target gene expressed in differentiated cells of human colonic epithelium and down-regulated in colon cancer. Mol Cancer Res 4: 645-653.

Carpenter B, McKay M, Dundas SR, Lawrie LC, Telfer C, Murray GI (2006) Heterogeneous nuclear ribonucleoprotein $\mathrm{K}$ is over expressed, aberrantly localised and is associated with poor prognosis in colorectal cancer. $\mathrm{Br}$ J Cancer 95: 921-927.

Chan CB, Kashemsant N (2006) Regulation of insulin secretion by uncoupling protein. Biochem Soc Trans 34: 802-805.

de Bilbao F, Arsenijevic D, Vallet P, Hjelle OP, Ottersen OP, Bouras C, Raffin Y, Abou K, Langhans W, Collins S, Plamondon J, Alves-Guerra MC, Haguenauer A, Garcia I, Richard D, Ricquier D, Giannakopoulos P (2004) Resistance to cerebral ischemic injury in UCP2 knockout mice: evidence for a role of UCP2 as a regulator of mitochondrial glutathione levels. J Neurochem 89: $1283-1292$.

Dentin R, Girard J, Postic C (2005) Carbohydrate responsive element binding protein (ChREBP) and sterol regulatory element binding protein-1c (SREBP-1c): two key regulators of glucose metabolism and lipid synthesis in liver. Biochimie 87: 81-86.

Diez-Fernandez C, Sanz N, Cascales M (1996) Changes in glucose-6-phosphate dehydrogenase and malic enzyme gene expression in acute hepatic injury induced by thioacetamide. Biochem Pharmacol 51: 1159-1163.

Duchen MR (2004) Roles of mitochondria in health and disease. Diabetes 53: 96-102.

Ekstedt M, Franzen LE, Mathiesen UL, Thorelius L, Holmqvist M, Bodemar G, Kechagias S (2006) Long-term follow-up of patients with NAFLD and elevated liver enzymes. Hepatology 44: 865-873.

Fromenty B, Robin MA, Igoudjil A, Mansouri A, Pessayre D (2004) The ins and outs of mitochondrial dysfunction in NASH. Diabetes Metab 30: 121-138.

Goffart S, Wiesner RJ (2003) Regulation and co-ordination of nuclear gene expression during mitochondrial biogenesis. Exp Physiol 88: 33-40.

Harrison SA, Torgerson S, Hayashi PH (2003) The natural history of nonalcoholic fatty liver disease: a clinical histopathological study. Am J Gastroenterol 98: 2042-2047.

Horimoto M, Fulop P, Derdak Z, Wands JR, Baffy G (2004) Uncoupling protein-2 deficiency promotes oxidant stress and delays liver regeneration in mice. Hepatology 39: 386-392.

Kelley DE, He J, Menshikova EV, Ritov VB (2002) Dysfunction of mitochondria in human skeletal muscle in type 2 diabetes. Diabetes 51: 2944-2950.

Kim S, Kim T (2003) Selection of optimal internal controls for gene expression profiling of liver disease. Biotechniques 35: 456-458, 460 .

Klimek-Tomczak K, Wyrwicz LS, Jain S, Bomsztyk K, Ostrowski J (2004) Characterization of hnRNP K proteinRNA interactions. J Mol Biol 342: 1131-1141.

Krauss S, Zhang CY, Lowell BB (2005) The mitochondrial uncoupling-protein homologues. Nat Rev Mol Cell Biol 6: $248-261$.

Mattiasson G, Shamloo M, Gido G, Mathi K, Tomasevic G, Yi S, Warden $\mathrm{CH}$, Castilho RF, Melcher T, Gonzalez- 
Zulueta M, Nikolich K, Wieloch T (2003) Uncoupling protein-2 prevents neuronal death and diminishes brain dysfunction after stroke and brain trauma. Nat Med 9: 1062-1068.

McLennan HR, Degli Esposti M (2000) The contribution of mitochondrial respiratory complexes to the production of reactive oxygen species. J Bioenerg Biomembr 32: 153-162.

Meyer LE, Machado LB, Santiago AP, da-Silva WS, De Felice FG, Holub O, Oliveira MF, Galina A (2006) Mitochondrial creatine kinase activity prevents reactive oxygen species generation: antioxidant role of mitochondrial kinases-dependent ADP re-cycling activity. J Biol Chem 281: 37361-37371.

Mikula M, Dzwonek A, Karczmarski J, Rubel T, Dadlez M, Wyrwicz LS, Bomsztyk K, Ostrowski J (2006) Landscape of the hnRNP $\mathrm{K}$ protein-protein interactome. Proteomics 6: 2395-2406.

Mootha VK, Lindgren CM, Eriksson KF, Subramanian A, Sihag S, Lehar J, Puigserver P, Carlsson E, Ridderstrale M, Laurila E, Houstis N, Daly MJ, Patterson N, Mesirov JP, Golub TR, Tamayo P, Spiegelman B, Lander ES, Hirschhorn JN, Altshuler D, Groop LC (2003) PGC1alpha-responsive genes involved in oxidative phosphorylation are coordinately downregulated in human diabetes. Nat Genet 34: 267-273.

Mounier C, Posner BI (2006) Transcriptional regulation by insulin: from the receptor to the gene. Can J Physiol Pharmacol 84: 713-724.

Neuschwander-Tetri BA, Caldwell SH (2003) Nonalcoholic steatohepatitis: summary of an AASLD Single Topic Conference. Hepatology 37: 1202-1219.

Ostrowski J (2006) Molecular medicine of the future - applications and pitfalls. Acta Pol Pharm 52: 329-332.

Ostrowski J, Bomsztyk K (2003) Nuclear shift of hnRNP K protein in neoplasms and other states of enhanced cell proliferation. Br J Cancer 89: 1493-1501.

Ostrowski J, Klimek-Tomczak K, Wyrwicz LS, Mikula M, Schullery DS, Bomsztyk K (2004) Heterogeneous nuclear ribonucleoprotein $\mathrm{K}$ enhances insulin-induced expression of mitochondrial UCP2 protein. J Biol Chem 279: 54599-54609.

Perez-Carreras M, Del Hoyo P, Martin MA, Rubio JC, Martin A, Castellano G, Colina F, Arenas J, Solis-Herruzo JA (2003) Defective hepatic mitochondrial respiratory chain in patients with nonalcoholic steatohepatitis. Hepatology 38: 999-1007.
Pessayre D, Fromenty B (2005) NASH: a mitochondrial disease. J Hepatol, 42: 928-940.

Pessayre D, Fromenty B, Mansouri A (2004) Mitochondrial injury in steatohepatitis. Eur J Gastroenterol Hepatol 16: 1095-1105.

Petersen KF, Befroy D, Dufour S, Dziura J, Ariyan C, Rothman DL, DiPietro L, Cline GW, Shulman GI (2003) Mitochondrial dysfunction in the elderly: possible role in insulin resistance. Science 300: 1140-1142.

Pongratz RL, Kibbey RG, Shulman GI, Cline GW (2007) Cytosolic and mitochondrial malic enzyme isoforms differentially control insulin secretion. J Biol Chem 282: 200-207.

Robey RB, Hay N (2006) Mitochondrial hexokinases, novel mediators of the antiapoptotic effects of growth factors and Akt. Oncogene 25: 4683-4696.

Saleh MC, Wheeler MB, Chan CB (2002) Uncoupling protein-2: evidence for its function as a metabolic regulator. Diabetologia 45: 174-187.

Sanz N, Diez-Fernandez C, Valverde AM, Lorenzo M, Benito M, Cascales M (1997) Malic enzyme and glucose 6-phosphate dehydrogenase gene expression increases in rat liver cirrhogenesis. Br J Cancer 75: 487-492.

Sreekumar R, Rosado B, Rasmussen D, Charlton M (2003) Hepatic gene expression in histologically progressive nonalcoholic steatohepatitis. Hepatology 38: 244-251.

Stump CS, Short KR, Bigelow ML, Schimke JM, Nair KS (2003) Effect of insulin on human skeletal muscle mitochondrial ATP production, protein synthesis, and mRNA transcripts. Proc Natl Acad Sci USA 100: 79968001.

Taanman JW (1999) The mitochondrial genome: structure, transcription, translation and replication. Biochim Biophys Acta 1410: 103-123.

Vandesompele J, De Preter K, Pattyn F, Poppe B, Van Roy N, De Paepe A, Speleman F (2002) Accurate normalization of real-time quantitative RT-PCR data by geometric averaging of multiple internal control genes. Genome Biol 3: research 0034.1-0034.11

Zhang CY, Baffy G, Perret P, Krauss S, Peroni O, Grujic D, Hagen T, Vidal-Puig AJ, Boss O, Kim YB, Zheng XX, Wheeler MB, Shulman GI, Chan CB, Lowell BB (2001) Uncoupling protein-2 negatively regulates insulin secretion and is a major link between obesity, beta cell dysfunction, and type 2 diabetes. Cell 105: 745-755. 